\title{
Two Approaches to Analyzing Data of Project Teams
}

\author{
Krzysztof Nowak* \& Kamila Pietrzak**
}

\begin{abstract}
Summary
In this chapter, we compare and discuss several statistical approaches to analyzing data obtained from team members. As an illustrative example, we analyze data obtained from 636 team members across 87 teams from 8 companies located in Poland using ordinary least squares multiple regression analysis, multiple regression with clustered standard errors, and mixed modeling. In the example, we analyze the relationship between team size and team gender composition concerning team climate. While a model building approach to hypothesis testing yields most similar results for multiple regression an a clustered standard error approach, a multilevel model yields results more similar to OLS regression when testing the significance of individual predictors, suggesting a clustered standard error correction is more prone to a type II error rate when testing model coefficients than an equivalent multilevel model. Finally, the implications of these observations to team data analyses are discussed.
\end{abstract}

Keywords: Leadership, Multilevel analysis, Project teams, Team climate

JEL: M12, C12, C18

\section{INTRODUCTION}

With the increasing prevalence of project-based management, the need to understand team cooperation has never been greater. Team cooperation provides a valuable competitive advantage in the modern market place. It is hard to emulate in the short term as it depends on human and organizational factors. However, choosing and implementing a method for analyzing data collected from teams has to be carefully considered, as it usually requires going beyond the most common statistical methods taught in most introductory statistical courses, as it requires considering the team context of the team member responses.

If we only consider aggregate, team-level variables (an example would be size, average productivity or number of conflicts in a team) and analyze the teams as distinct units, team data can be analyzed using any of the standard statistical methods (analysis of variance or multiple regression, for example) as long as the standard assumptions are met. If we consider team-member variables (ex. gender or age of team members or how each member views the team), we run into a problem, since team members are usually more similar to members of a team they belong to than to members of another team. This similarity violates the principle of independence of observations assumed in ordinary least squares (OLS) regression and is known as nesting. This results in the underestimation of standard errors of regression coefficients and smaller $\mathrm{p}$ values, leading to increased rate of type I error (finding an effect even when it is not present) (Greene, 2003). The problem is exuberated when:

- the teams are large;

- team members tend to be alike, meaning their values of one or more variables are more similar within a team than between teams;

- there is a sizeable average correlation of one or more variables within teams.

\footnotetext{
* Faculty of Management, University of Warsaw, Poland, https://orcid.org/0000-0001-9615-1222

** Faculty of Management, University of Warsaw, Poland, https://orcid.org/0000-0001-7250-7503
} 
Thus, the problem of nesting is especially important when:

- we consider team-level variables, as they are constant within a team;

- when team members rate team characteristics, as we can expect people will tend to give similar ratings of the same team;

- as the teams get larger, so the problem will usually be more meaningful when considering teams of 10 people than pairs of 2 .

There are various methods of dealing with nesting. One approach is to add dichotomous variables indicating each team and thus accounting for a between-team variance. Although this can be a good way of dealing with correlated observations within teams if we have only variables on the team member level, it fails to correct for the inflated standard errors caused by team-level variables. Additionally, we may want to take into consideration the team context, a problem frequently encountered when analyzing group data (Sagan, 2009).

We will concentrate on two other approaches of correcting for nesting: clustered standard errors (Hox, Moerbeek \& Van de Schoot, 2017) and multilevel modeling (Stock \& Watson, 2008). The first is widely used, as it enables one to use a standard regression procedure and is easily performed with some standard statistical software. The second one requires a large sample size at the team level (Snijders, 2005) (as we are estimating team-level model as well as an individual level model) and a more nuanced theoretical understanding of modeling the team and individual-level (Twiskt, 2010). Despite this, it has been gaining popularity in economics and business research, because it allows for testing numerous individuals, and context (team, institution, country et cetera) level relationships simultaneously (Peterson, Arregle \& Martin, 2012). We will compare these to performing a naïve OLS multiple regression, that does not take the problem of nesting into account to examine how the analyses results differ when accounting for nesting.

\section{EXAMPLE OF PROJECT TEAM STUDY}

Research Question: How is the team size and gender composition related to team climate in a sample of companies located in Poland?

\section{Hypotheses:}

Team-member level:

H1. Team member gender is related to team climate.

Team level:

$\mathrm{H} 2$. There is a relationship between team size, team leader gender, and/or percentage of women in the team with team climate.

Interaction of Team-member and team level:

H3. There is a relationship between the interaction of team leader and team member gender with respect to team climate.

\section{JUSTIFICATION OF A RESEARCH QUESTION AND HYPOTHESES}

Team climate. In this study, we were interested in the relations between team climate and the gender composition and size on a sample of project teams located in Poland. We examined team climate as a construct comprising of five dimensions related to those listed by Patrick Lencioni (Lencioni, 2016):

- Trust

- Open discussion of conflict 
- Team involvement

- Personal accountability

- Attention to results

This is not an accident that trust within a team is listed first. It is crucial for effectiveness of work that team members trust each other and trust the leader. Trust provides them with a degree of comfort and safety, and allows each person to focus on his tasks, rather than wasting energy on double checking others' work. It is a cornerstone, on which other elements build the efficient work environment: problem solving, commitment, accountability and goal oriented approach. In the situation of absence of trust, employees are afraid of asking for help in solving a problem, showing weaknesses or even sharing opinions. As a result, the knowledge transfer between team members is limited, and this can impact the work delivered by the group.

Trust leads to the second important dimension of the team climate: open discussion of conflicts. It manifests itself with the readiness to share comments and opinions with other members of the group. In such situations important ideas or warning signals about potential risks for task delivery reach the leader with ease. Simultaneously, ideas are discussed before being accepted by the rest of the team because team members do not fear open conflict with other team members. Both of these factors can positively influence the quality of the delivered product.

Team involvement is directly related to the proactive attitude possible in a team where trust and open discussion of conflicts are the norm. In a team with high involvement, people commit and care about team goals. This also is closely related to a higher personal accountability. This means that team members are personally and willingly taking on the responsibility of finishing a project, task or goal.

Finally, attention to results, meaning how much team members value and pay attention to common team goals as opposed to personal goals that come at the expense of team efforts. This enables the team to work as a whole, ensuring that the tasks relevant to the project are completed in a timely and organized fashion.

Leadership gender and team climate. Leader and team member gender seem to be related to perceived team climate. This can occur due to a combination of factors. Women and men are judged differently by team members and superiors when performing tasks. A selection bias can also be present: it is usually harder for a woman to attain a leadership position, that it is for a man. Thus, she has to display a different set of characteristics than her male counterparts. Another factor may be the support and perceptions of fellow leaders as well as teammates, which may influence the team climate.

An example of how gender composition is related to the team climate comes from a study performed in three multinational companies based in China, on 59 managers and 245 subordinates: 17 female managers and their 69 subordinates and 42 male managers and their 176 subordinates. The results have indicated that avoidance of a conflict perceived by teams was more frequent in male managers than it was in females (Yang \& Li, 2018). It may suggest that female leaders are more focused on team interactions than male leaders, according to authors of the study.

Although leadership style may be different between female and male leaders, their efficiency does not depend on gender. Despite this, female leaders are perceived as less efficient (Appelbaum, Audet \& Miller, 2003). If this expectation is shared by team members, it may bear on the team climate. Failing that external situations also differ, which may have an impact on team climate. When the company performs well, female leaders are rewarded less then male leaders. However, when the company's economic performance is poor female leaders are also punished less (Kulich, Ryan \& Haslam, 2007)

Leaders are perceived to possess features and attitudes more often associated with being a man than with being a woman - namely decision making, assertiveness and the ability for strategic thinking (Wille, 2018; Schein, 1975). Additionally, women in managerial roles are likely (as well 
as male managers) to choose and support men in their way to leadership. Meanwhile, women face challenges with "sticky floors", and a "glass ceiling", on the way. Some challenges may be related with behaviors, such as being too perfectionistic, hesitant with reaching for power, and not building strategic networks (Shambaugh, 2007).

Additionally, research has shown a tendency to evaluate female leaders less favorably than male leaders but this effect was small (Eagly, Makhijani \& Klonsky, 1992). The devaluation was stronger if women were in high manager positions in male dominated environment and when evaluation was performed my men. An interesting phenomenon associated with leadership assignment in femaledominant groups was called the "glass escalator" (Williams, 1992). Men who work in traditionally female professions, such as nursing and education, receive support and even pressure to move to managerial roles. Thus, not only can we can expect more men than women in managerial positions in our sample, but also an interaction effect, where females evaluate the climate of female-lead teams more negatively.

\section{PARTICIPANTS}

The sample consists of 636 employees (37\% of them were women from retail, the automotive sector and finance sector). Among 87 teams $22(25 \%)$ had a female leader. The typical (median) team had 6 members (the smallest had 3 and the largest had 33). All team members filled the survey TEAM PLUS, which diagnoses the climate of teamwork assessed by its members using 10-point Likerttype scale, where -5 indicates "completely disagree" and +5 indicates "completely agree".

\section{MATERIALS}

TEAM PLUS TEST is a tool used by managers who want to learn how the team sees themselves. The tool is based on the concept developed and described by P. Lencioni regarding team dysfunctions, which has been described earlier in this chapter. Questions comprising these five dimensions, as well as their distribution in the teams, can be found in the appendix.

\section{STATISTICAL PROCEDURE}

Our study contrasts the results of the analysis of the same data set by 3 methods:

(1) ordinary least squares multiple regression,

(2) multiple regression with clustered standard errors, and

(3) multilevel modeling.

Analyses were carried out for each of the 5 team climate variables separately and were divided into two parts. Answers to the team climate items were all standardized within people to take into account the individual response styles of the team-members. Next, the team climate variables were computed by taking the mean of the items comprising a dimension of team climate (see materials section). Additionally, the TEAM SIZE was transformed with a logarithm transform because we assume team climate changes linearly with every doubling of team size, so an additional person has less of an effect on larger teams than it has on smaller teams. In order to check how the percentage of men and women in the team is related to team climate we centered the percentage of women in the team to a mean of 0 and added the square of that variable to check for non-linear effects.

Testing the hypotheses was first performed using a model-building approach, where the variables were added into three successive models and the significance of the improvement in explaining team climate was assessed using an appropriate statistical test. The FIRST model had only teammember level variables: member's gender, as the predictor. The SECOND model added team-level 
predictors: team leader's gender, the logarithm of team size, and the percentage of females in the team, along with the square of the percentage of female in the team, to test for the effect of gender composition on team climate. The THIRD model added an interaction term of team leader and team member gender to test the interaction hypothesis between team member and team level variables. F test was used for the OLS multiple regression, an F test with an appropriate correction for a covariance structure that accounted for clustering for the regression with clustered standard errors, and a Likelihood ratio Chi-squared test for the multilevel models.

Lastly the coefficient estimates, their standard errors and significance values of the full models in the previous section were compared. Separate tables were created for each of the climate variables. Analyses were performed using the R statistical environment (R Core Team, 2018) with the lme4 (Bates, Maechler, Bolker \& Walker, 2015) package for multilevel modeling and a custom function for computing the clustered standard error correction to match those available via the cluster option in the regress command in the Stata statistical program (StataCorp, 2017).

\section{DESCRIPTIVE STATISTICS}

The descriptive statistics of the predictors can be seen in Table 1. Overall, there was a moderate to high correlation between the predictors. This is expected in the analysis of team data, as all withinteam correlations of team level variables are equal to 1 . On the other hand, member gender is quite highly correlated with the percent of woman in the team. It is quite clear from the descriptive statistics that it is important to consider the problem of team members nested within teams in our example.

Table 1. Descriptive statistics of the predictors

\begin{tabular}{|c|c|c|c|c|c|c|c|}
\hline Level & Variable name & Mean(SD) & Range & & Corre & tions & \\
\hline member & gender & $238(0.37)^{*}$ & $0-1$ & gender & leader gender & $\%$ women & $\%$ women $^{2}$ \\
\hline team & leader gender & $185(0.29)^{*}$ & $0-1$ & 0.58 & - & - & - \\
\hline team & $\%$ of women & $0(1.00)$ & $0.37-0.62$ & 0.50 & 0.48 & - & - \\
\hline team & {$[\% \text { of women }]^{2}$} & $0.10(0.1)$ & $0-0.39$ & 0.50 & 0.48 & - & - \\
\hline team & $\ln (n)$ & $2.16(0.59)$ & $1.10-3.50$ & 0.23 & 0.46 & 0.23 & 0.23 \\
\hline
\end{tabular}

* For the team member and team leader gender, variable number of women, and their proportion the dataset is shown. $0=$ man, $1=$ woman.

The distribution of the climate variables within teams is shown in the appendix. The mean of the variables is quite close to 0 , and their standard error is close to .35 , due to the fact that each is constructed as the mean of eight items standardized within individuals.

While the means of the mean team responses are quite evenly dispersed around the mean value, there is a quite high deviation from this value in some of the ratings within a team, this can indicate it is important to examine the team member level and not only the teams at the aggregate level.

\section{HYPOTHESIS TESTING USING OLS REGRESSION, CLUSTERED STANDARD ERRORS AND MULTILEVEL MODELING}

First, let us examine Table 2 in which hypothesis tests were performed by testing OLS multiple regression models against each other. This type of analysis disregards the problem of nesting, but is the simplest of the three to use, as virtually all statistical packages have it built in. As we can 
see, the team member gender (the Member model) is significantly related to open discussion of conflicts, team involvement and personal accountability. Team gender composition and team size (Member + Team model) is significantly related to trust, attention to results and team involvement. Additionally, open discussion of conflicts is significantly related to the interaction of team leader gender and team member gender.

Examining the coefficients of the significant models, it turns out trust is related to the squared term of team gender, with trust being significantly lower in more heterogeneous groups $(\mathrm{B}=-1.12(0.34)$, $t=-3.25, p=0.001)$.

Women are less open to the discussion of conflicts with female leaders $(\mathrm{B}=-0.18(0.05)$, $t=-3.34, p<0.001$ ) with this effect being due to women being less open to discussion of conflict within female lead teams than within male led teams $(\mathrm{B}=-0.37(0.12), t=-2.94, p=0.003)$.

Team involvement was higher for teams with a higher percentage of women $(\mathrm{B}=0.25(0.12)$, $t=2.00, p=0.03)$, and was rated as higher by women than it was rated by men $(\mathrm{B}=0.12(0.04)$, $t=2.42, p=0.02)$. The rating of personal accountability within a team was also rated as higher by women than it was rated by men $(\mathrm{B}=0.20(0.05), t=3.85, p<0.001)$. Finally, attention to results was related to a combination of team-level variables, with attention to results being higher within more heterogeneous teams $(\mathrm{B}=1.26(0.39), t=3.24, p=0.001)$, larger groups $(\mathrm{B}=0.14(0.06)$, $t=2.27, p=0.02)$ and lower for teams led by females $(\mathrm{B}=-0.09(0.34), t=-2.01, p=0.04)$.

Table 2. Hypotheses tests using OLS stepwise regression

\begin{tabular}{|c|c|c|c|}
\hline Model & Member & Member + Team & Member x Team \\
\hline Degrees of freedom & 1,624 & 4,620 & 4,619 \\
\hline \multicolumn{4}{|l|}{ Trust } \\
\hline Test & 3.35 & 4.61 & 0.71 \\
\hline$p$ & 0.07 & 0.00 & 0.40 \\
\hline \multicolumn{4}{|c|}{ Open discussion of conflicts } \\
\hline Test & 11.35 & 2.32 & 6.21 \\
\hline$p$ & 0.00 & 0.06 & 0.01 \\
\hline \multicolumn{4}{|l|}{ Team involvement } \\
\hline Test & 5.98 & 4.20 & 1.13 \\
\hline$p$ & 0.01 & 0.00 & 0.29 \\
\hline \multicolumn{4}{|l|}{ Personal accountability } \\
\hline Test & 14.82 & 0.50 & 1.40 \\
\hline$p$ & 0.00 & 0.73 & 0.24 \\
\hline \multicolumn{4}{|l|}{ Attention to results } \\
\hline Test & 0.08 & 4.36 & 1.17 \\
\hline$p$ & 0.77 & 0.00 & 0.28 \\
\hline
\end{tabular}

Note. The statistical test performed was an F test, and the first and second degrees of freedom for each successive test are separated by a comma in the "degrees of freedom" row. 
A very similar pattern emerges when examining the table of tests with a clustered standard error correction. The difference is that the test statistic is smaller, and the values have a higher $p$ value. However, in our case this was not sufficient to push any of the significant models into the area of non-significance, so the results are qualitatively unchanged. Examining the significant model coefficients, it turns out trust is (again) lower in more heterogeneous groups $(\mathrm{B}=-1.12(0.57)$, $t=-1.92, p=0.049)$, women are less willing to openly discuss conflicts than men $(\mathrm{B}=-0.18(0.07)$, $t=-2.48, p=0.01)$ and this effect is due to females being less open to discuss conflict in female led groups $(\mathrm{B}=-0.37(0.15), t=-2.37, p=0.02)$. Team involvement is rated as higher by women than it is by men $(\mathrm{B}=0.12(0.05), t=2.23, p=0.03)$. Females tend to also rate their team higher on personal accountability $(\mathrm{B}=-0.20(0.05), t=3.98, p<0.001)$, and attention to results is higher in teams that are more heterogeneous $(\mathrm{B}=1.26(0.55), t=2.27, p=0.02)$.

Table 3. Hypotheses tests using clustered standard error corrected stepwise regression

\begin{tabular}{|c|c|c|c|}
\hline Model & Member & Member + Team & Member x Team \\
\hline Degrees of freedom & 1,624 & 4,620 & 4,619 \\
\hline \multicolumn{4}{|l|}{ Trust } \\
\hline Test & 1.31 & 2.80 & 0.31 \\
\hline$p$ & 0.25 & 0.03 & 0.58 \\
\hline \multicolumn{4}{|c|}{ Open discussion of conflicts } \\
\hline Test & 6.13 & 0.97 & 3.94 \\
\hline$p$ & 0.01 & 0.42 & 0.05 \\
\hline \multicolumn{4}{|l|}{ Team involvement } \\
\hline Test & 4.95 & 8.69 & 1.07 \\
\hline$p$ & 0.03 & $<0.001$ & 0.3 \\
\hline \multicolumn{4}{|l|}{ Personal accountability } \\
\hline Test & 15.85 & 0.57 & 1.32 \\
\hline$p$ & 0 & 0.68 & 0.25 \\
\hline \multicolumn{4}{|l|}{ Attention to results } \\
\hline Test & 0.05 & 2.27 & 0.65 \\
\hline$p$ & 0.82 & 0.06 & 0.42 \\
\hline
\end{tabular}

Note. The statistical test performed was a Wald $\mathrm{F}$ test with a covariance structure correction for clustering, and the first and second degrees of freedom for each successive test are separated by a comma in the "degrees of freedom" row.

Finally, the pattern somewhat changes with the mixed model approach to analyzing team data, although the differences are not drastically big. Trust is no longer related to team gender composition and size, and team involvement is no longer related to member gender. The pattern of females being less inclined to openly discuss conflicts in female than in male led teams persists $(\mathrm{B}=-0.34(0.13)$, $t=-2.60, p=0.02)$. Similarly, team involvement is greater in groups that have a higher percentage of women $(\mathrm{B}=0.25(0.12), t=2.04, p=0.04)$, and, like in the OLS analysis, attention to results is greater in more heterogeneous $\mathrm{B}=1.40(0.58), t=2.40, p=0.01)$ and larger $(\mathrm{B}=0.22(0.10)$, $t=2.30, p=0.02$ ) teams. 
Table 4. Hypotheses tests using multilevel modeling

\begin{tabular}{|c|c|c|c|}
\hline Model & Member & Member+Team & Member x Team \\
\hline Degrees of freedom & 1 & 4 & 1 \\
\hline \multicolumn{4}{|l|}{ Trust } \\
\hline Test & 0.40 & 7.77 & 0.03 \\
\hline$p$ & 0.53 & 0.10 & 0.87 \\
\hline \multicolumn{4}{|c|}{ Open discussion of conflicts } \\
\hline Test & 6.17 & 7.77 & 5.20 \\
\hline$p$ & 0.01 & 0.10 & 0.02 \\
\hline \multicolumn{4}{|l|}{ Team involvement } \\
\hline Test & 2.23 & 14.07 & 1.14 \\
\hline$p$ & 0.14 & 0.01 & 0.29 \\
\hline \multicolumn{4}{|l|}{ Personal accountability } \\
\hline Test & 12.74 & 2.02 & 1.14 \\
\hline$p$ & 0.00 & 0.73 & 0.29 \\
\hline \multicolumn{4}{|l|}{ Attention to results } \\
\hline Test & 0.21 & 10.74 & 0.50 \\
\hline$p$ & 0.65 & 0.03 & 0.48 \\
\hline
\end{tabular}

Note. The statistical test performed was a likelihood ratio Chi-squared.

\section{COMPARING COEFFICIENTS OF THE FULL MODELS}

Tables 5 through 9 compare the regression coefficients of the full (Member $\mathrm{x}$ Team) models estimated using OLS multiple regression, clustered standard errors, and multilevel analysis for each of the team climate variables. This was done to illustrate the differences in the estimated parameters and statistical tests, as this is often how hypothesis testing is done, instead of the above-shown model-comparison method. Here the advantages of a multilevel approach become readily apparent over the clustered standard error correction. In fact, only two parameters found to be significant in the OLS models were not significant in the multilevel model: less open discussion of conflicts in teams with female leaders and less attention to results in teams with a female leader. In fact, the multilevel model had one coefficient that was significant only in this, but not in the other two models: there was a smaller tendency for open discussion of conflict in bigger teams. In contrast, most of the significant parameters found in the OLS regression models, were not significant after applying the clustered standard error correction, and both of those which were also found to be significant in the multilevel models.

As we can see in Table 5, B coefficients of the model are identical in the OLS and clustered standard errors corrected models, the standard error estimates and statistical tests are the only ones that show some variation. Trust was significantly related to the gender heterogeneity in the OLS regression model, as well as in the multilevel model, but not in the clustered standard errors corrected model. This stands in contrast to the model building hypothesis testing. As it was found, it was the clustered standard error model that was related to gender heterogeneity, but not the multilevel model. 
This could be due to a greater sensitivity of model misspecification through adding a non-significant leader gender $\mathrm{x}$ member gender interaction term in the former than in the latter.

Table 5. OLS, clustered standard error corrected coefficients and multilevel coefficients along with statistical tests and significance levels of the member $\mathrm{x}$ team models for the trust variable

\begin{tabular}{|c|c|c|c|c|c|c|c|c|c|}
\hline & \multicolumn{3}{|c|}{ OLS } & \multicolumn{3}{|c|}{ Clustered SE } & \multicolumn{3}{|c|}{ Multilevel } \\
\hline & B & SE & $p$ & B & SE & $p$ & B & SE & $p$ \\
\hline intercept & 0.35 & 0.14 & 0.01 & 0.35 & 0.18 & 0.05 & 0.36 & 0.18 & 0.05 \\
\hline gender & 0.04 & 0.09 & 0.70 & 0.04 & 0.08 & 0.66 & 0.01 & 0.09 & 0.92 \\
\hline leader gender & 0.05 & 0.10 & 0.65 & 0.05 & 0.18 & 0.80 & 0.01 & 0.13 & 0.92 \\
\hline$\%$ women & -0.02 & 0.15 & 0.89 & -0.02 & 0.25 & 0.93 & -0.05 & 0.19 & 0.82 \\
\hline$(\% \text { of women })^{2}$ & -0.99 & 0.38 & 0.01 & -0.99 & 0.65 & 0.13 & -1.05 & 0.51 & 0.04 \\
\hline $\log (n)$ & -0.07 & 0.06 & 0.20 & -0.07 & 0.08 & 0.38 & -0.07 & 0.08 & 0.37 \\
\hline leader gender $\mathrm{x}$ gender & -0.13 & 0.16 & 0.40 & -0.13 & 0.23 & 0.58 & -0.02 & 0.16 & 0.90 \\
\hline
\end{tabular}

Table 6. OLS, clustered standard error corrected coefficients and multilevel coefficients along with statistical tests and significance levels of the member $\mathrm{x}$ team models for the open discussion of conflicts variable

\begin{tabular}{|c|c|c|c|c|c|c|c|c|c|}
\hline & \multicolumn{3}{|c|}{ OLS } & \multicolumn{3}{|c|}{ Clustered SE } & \multicolumn{3}{|c|}{ Multilevel } \\
\hline & B & SE & $p$ & B & SE & $p$ & B & SE & $p$ \\
\hline intercept & 0.11 & 0.12 & 0.38 & 0.11 & 0.18 & 0.56 & 0.27 & 0.16 & 0.11 \\
\hline gender & 0.00 & 0.08 & 1.00 & 0.00 & 0.07 & 1.00 & -0.01 & 0.07 & 0.85 \\
\hline leader gender & 0.24 & 0.09 & 0.01 & 0.24 & 0.12 & 0.05 & 0.17 & 0.12 & 0.15 \\
\hline$\%$ of women & -0.16 & 0.14 & 0.24 & -0.16 & 0.17 & 0.35 & -0.10 & 0.18 & 0.57 \\
\hline$(\% \text { of women })^{2}$ & 0.11 & 0.34 & 0.76 & 0.11 & 0.51 & 0.84 & -0.21 & 0.46 & 0.65 \\
\hline $\log (\mathrm{n})$ & -0.09 & 0.05 & 0.07 & -0.09 & 0.08 & 0.24 & -0.15 & 0.07 & 0.05 \\
\hline leader gender $\mathrm{x}$ gender & -0.34 & 0.14 & 0.01 & -0.34 & 0.17 & 0.05 & -0.31 & 0.14 & 0.02 \\
\hline
\end{tabular}

In all models there was a significant interaction, it is shown in Figure 1 for the OLS and Clustered SE model (the interaction plot for the multilevel model was almost identical, so it is not shown). Women were less ready to openly discuss conflict in female led groups than they were in male-led groups. In the OLS regression case the leader's gender was significantly related to the discussion of conflicts, having members of teams led by females more openly discussing conflicts than it was in teams led by males. This finding is most probably due to artificially low standard errors when disregarding the team structure of the data. On the other hand the number of team members was found to be significantly negatively related to the open discussion of conflicts within the team in the multilevel model, but not in the other two models. 
Figure 1. Interaction plot of open discussion of conflicts in the OLS regression as a function of the interaction of gender and leaders' gender.

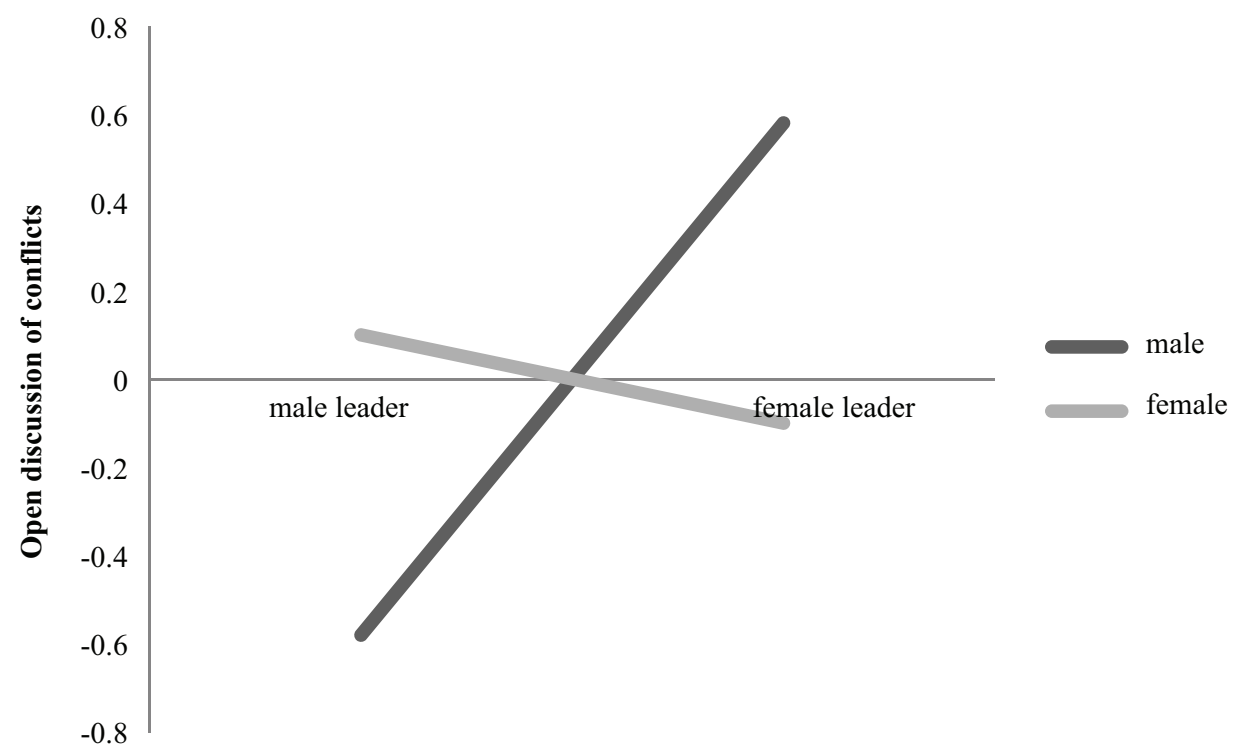

Table 7. OLS, clustered standard error corrected coefficients and multilevel coefficients along with statistical tests and significance levels of the member $\mathrm{x}$ team models for the team involvement variable.

\begin{tabular}{|c|c|c|c|c|c|c|c|c|c|}
\hline & \multicolumn{3}{|c|}{ OLS } & \multicolumn{3}{|c|}{ Clustered SE } & \multicolumn{3}{|c|}{ Multilevel } \\
\hline & B & SE & $p$ & $\mathrm{~B}$ & SE & $p$ & $\mathrm{~B}$ & SE & $p$ \\
\hline intercept & 0.00 & 0.11 & 0.98 & 0.00 & 0.13 & 0.98 & 0.00 & 0.11 & 0.97 \\
\hline gender & -0.07 & 0.07 & 0.35 & -0.07 & 0.07 & 0.35 & -0.06 & 0.07 & 0.36 \\
\hline leader gender & 0.00 & 0.08 & 0.98 & 0.00 & 0.09 & 0.98 & 0.00 & 0.08 & 0.97 \\
\hline$\%$ women & 0.24 & 0.12 & 0.05 & 0.24 & 0.14 & 0.08 & 0.24 & 0.12 & 0.05 \\
\hline$(\% \text { of women })^{2}$ & 0.06 & 0.30 & 0.84 & 0.06 & 0.27 & 0.82 & 0.07 & 0.31 & 0.81 \\
\hline $\log (n)$ & 0.05 & 0.04 & 0.27 & 0.05 & 0.04 & 0.27 & 0.05 & 0.05 & 0.30 \\
\hline leader gender $\mathrm{x}$ gender & 0.13 & 0.12 & 0.29 & 0.13 & 0.13 & 0.30 & 0.12 & 0.12 & 0.32 \\
\hline
\end{tabular}

With a higher percentage of women there was an increased level of involvement both for the OLS regression, as well as the multilevel model. Again, the clustered standard error approach yielded no significant results.

Although gender was found to be significantly related to the rating of personal accountability in the model-building approach, in the full model hypotheses testing there is no significant effect of any variable of the model. This is most probably due to a quite high correlation of team member gender and the percentage of females in the team, which decreases the values of statistical tests for these two variables if they are entered in the same model, although the model itself can significantly explain the dependent variable. 
Table 8. OLS, clustered standard error corrected coefficients and multilevel coefficients along with statistical tests and significance levels of the member $\mathrm{x}$ team models for the personal accountability variable

\begin{tabular}{|c|c|c|c|c|c|c|c|c|c|}
\hline & \multicolumn{3}{|c|}{ OLS } & \multicolumn{3}{|c|}{ Clustered SE } & \multicolumn{3}{|c|}{ Multilevel } \\
\hline & B & $\mathrm{SE}$ & $p$ & B & $\mathrm{SE}$ & $p$ & B & $\mathrm{SE}$ & $p$ \\
\hline intercept & 0.06 & 0.11 & 0.60 & 0.06 & 0.12 & 0.62 & 0.06 & 0.13 & 0.66 \\
\hline gender & 0.11 & 0.08 & 0.14 & 0.11 & 0.06 & 0.08 & 0.12 & 0.07 & 0.12 \\
\hline leader gender & -0.02 & 0.09 & 0.85 & -0.02 & 0.09 & 0.85 & -0.01 & 0.10 & 0.94 \\
\hline$\%$ of women & 0.10 & 0.13 & 0.46 & 0.10 & 0.17 & 0.57 & 0.10 & 0.14 & 0.47 \\
\hline$(\% \text { of women })^{2}$ & -0.23 & 0.32 & 0.48 & -0.23 & 0.30 & 0.45 & -0.15 & 0.37 & 0.69 \\
\hline $\log (n)$ & -0.03 & 0.05 & 0.54 & -0.03 & 0.05 & 0.52 & -0.03 & 0.06 & 0.57 \\
\hline leader gender $\mathrm{x}$ gender & 0.16 & 0.13 & 0.24 & 0.16 & 0.14 & 0.25 & 0.14 & 0.13 & 0.30 \\
\hline
\end{tabular}

Note: Significant $\mathrm{p}$ values are shaded.

Table 9. OLS, clustered standard error corrected coefficients and multilevel coefficients along with statistical tests and significance levels of the member $\mathrm{x}$ team models for the attention to results variable

\begin{tabular}{|c|c|c|c|c|c|c|c|c|c|}
\hline & \multicolumn{3}{|c|}{ OLS } & \multicolumn{3}{|c|}{ Clustered SE } & \multicolumn{3}{|c|}{ Multilevel } \\
\hline & $\mathrm{B}$ & SE & $p$ & $\mathrm{~B}$ & SE & $p$ & $\mathrm{~B}$ & SE & $p$ \\
\hline intercept & -0.53 & 0.15 & 0.00 & -0.53 & 0.21 & 0.01 & -0.73 & 0.22 & 0.00 \\
\hline gender & -0.08 & 0.10 & 0.44 & -0.08 & 0.10 & 0.43 & -0.06 & 0.09 & 0.55 \\
\hline leader gender & -0.26 & 0.12 & 0.02 & -0.26 & 0.21 & 0.22 & -0.16 & 0.16 & 0.30 \\
\hline$\%$ of women & -0.16 & 0.17 & 0.37 & -0.16 & 0.29 & 0.59 & -0.24 & 0.23 & 0.29 \\
\hline$(\% \text { of women })^{2}$ & 1.06 & 0.43 & 0.01 & 1.06 & 0.60 & 0.08 & 1.28 & 0.61 & 0.04 \\
\hline $\log (n)$ & 0.15 & 0.06 & 0.02 & 0.15 & 0.08 & 0.08 & 0.22 & 0.10 & 0.02 \\
\hline leader gender $\mathrm{x}$ gender & 0.19 & 0.17 & 0.28 & 0.19 & 0.23 & 0.42 & 0.12 & 0.17 & 0.49 \\
\hline
\end{tabular}

Note: Significant $\mathrm{p}$ values are shaded.

Three variables, leader gender, gender heterogeneity, and team size, were found to be significantly related to the attention to results, were non-significant after correcting for the clustered nature of the data. Two of them were also significant in the multilevel model. As the gender heterogeneity was grater and as the team size increased the attention to results also grew.

\section{DISCUSSION OF RESULTS}

The model building approach and comparison of the full model coefficients confirmed hypotheses $\mathrm{H} 2$ and H3, when used with any of the methods: OLS with clustered standard errors or multilevel modeling. However, the only one which confirmed H1 was a model-building approach. This is not surprising, as team member gender is highly correlated to team gender composition, so including 
the team-level variable could mask the relationship of member gender to team climate. A result that was consistent in the analyses was that trust was lower in more gender heterogeneous groups, open discussion of conflict was related to the interaction of leader and member gender, women rated the team as having a higher personal accountability and that a greater gender heterogeneity, as well as possibly a greater team size, was positively related to attention to results. Very few significant results were found in the full model coefficient comparison approach, as opposed to the model building approach when the clustered standard error correction was applied to regular OLS estimates, indicating that the approach can be overly conservative compared to multilevel modeling when adding non-significant predictors.

\section{CLOSING REMARKS}

In this example two approaches to dealing with team data were explored and compared to a standard ordinary least squares regression approach. Depending on how the researcher wants to conduct hypotheses tests, each has its advantages. If the researcher intends to use a model comparison approach and wants to only examine the coefficients of the significant models, a clustered standard error approach seems to quite closely resemble that of an OLS regression.

Contrarily, if a researcher wants to perform hypotheses tests based on a full model derived from theory and only focuses on a coefficient tests, a multilevel approach seems more appropriate as a clustered SE approach in this case seemed to be underpowered yielding very few significant coefficients. Furthermore, all of the effects found in the clustered SE approach were also found when using the multilevel analysis. The multilevel coefficient tests were not only very similar to the uncorrected OLS coefficient tests, but also reviled an additional effect, suggesting that one can find additional effects when performing a multilevel model, which is unlikely using the clustered standard error correction to OLS parameters.

\section{Literature}

Appelbaum, S. H., Audet, L., \& Miller, J. C. (2003). Gender and leadership? Leadership and gender? A journey through the landscape of theories. Leadership \& Organization Development Journal, 24(1), 43-51, http:// dx.doi.org/10.1108/01437730310457320

Bates, D., Maechler. M., Bolker, B., \& Walker, S. (2015). Fitting Linear Mixed-Effects Models using lme4. Journal of Statistical Software, 67(1), 1-48, http://dx.doi.org/10.18637/jss.v067.i01

Cullen, J. B., Parboteeah, K. P., \& Hoegl, M. (2004). Cross-national differences in managers' willingness to justify ethically suspect behaviors: A test of institutional anomie theory. Academy of Management Journal, 47(3), 411-421, http://dx.doi.org/10.2307/20159590

Eagly, A. H., Makhijani, M. G., \& Klonsky, B. G. (1992). Gender and the evaluation of leaders: A meta-analysis. Psychology Bulletin, 111, 3-22, http://dx.doi.org/10.1037/0033-2909.111.1.3

Greene, W. H. (2003). Econometric analysis. Pearson Education India.

Hox, J. J., Moerbeek, M. A, \& Van de Schoot, R. (2017). Multilevel analysis: Techniques and applications, Routledge, http://dx.doi.org//10.4324/9781315650982

Lencioni P. (2016). Przezwyciężanie pięciu dysfunkcji pracy zespołowej: praktyczny przewodnik dla liderów, menedżerów, moderatorów, Warszawa: MT Biznes.

Kulich, C., Ryan, M. K., \& Haslam, S. A. (2007). Where is the romance for women leaders? The effects of gender on leadership attributions and performance based pay, Applied Psychology, 56, 582-601, http:// dx.doi.org/10.1111/j.1464-0597.2007.00305.x

Peterson, M. F., Arregle, J.-L., \& Martin, X. (2012). Multilevel models in international business research. Journal of International Business Studies, 43(5), 451-457.

R Core Team (2018). R: A language and environment for statistical computing. $R$ Foundation for Statistical Computing, Vienna, Austria. Retrieved from https://www.R-project.org/ (19.10.2018)

Sagan, A. (2009). Wielopoziomowe analizy strukturalne w analizie postępowania konsumentów - porównanie modeli pomiarowych. Zeszyty Naukowe Nr 756 Uniwersytetu Ekonomicznego w Krakowie. 
Schein, V. E. (1975). Relationships between sex role stereotypes and requisite management characteristics among female managers. Journal of Applied Psychology, 60, 340-344, http://dx.doi.org/10.1037/h0076637

Shambaugh, R. (2007). It's not a glass ceiling, it's a sticky floor: Free yourself from the hidden behaviors sabotaging your career success. New York, NY: McGraw Hill.

Snijders, T. A. (2005). Power and sample size in multilevel modeling. Encyclopedia of statistics in behavioral science, 3, 1570-1573.

StataCorp (2017). Stata Statistical Software: Release 15. College Station, TX: StataCorp LLC.

Stock, J. H. \& Watson, M. W. (2008). Heteroskedasticity-robust standard errors for fixed effects panel data regression. Econometrica, 76(1), 155-174, http://dx.doi.org/10.1111/j.0012-9682.2008.00821.x

Twiskt, J. W. R. (2010). Analiza wielopoziomowa - przyktady zastosowań (Applied Multilevel Analysis). Oficyna Wydawnicza SGH.

Wieczorkowska G. (1993). Pułapki statystyczne. In Z. Smoleńska (Ed.) Badania nad rozwojem w okresie dorastania. (pp. 211-234). Warszawa: Instytut Psychologii PAN.

Wille, B., Wiernik, B. M., Vergauwe, J., Vrijdags, A., T, N., \& Trbovic, N. (2018). Personality characteristics of male and female executives: Distinct pathways to success? Journal of Vocational Behavior.

Williams Ch. L., (1992). The Glass Escalator: Hidden Advantages for Men in the „Female” Professions, Social Problems, 39(3), 253-267, http://dx.doi.org/10.2307/3096961

Yang, I., \& Li, L. M. (2018). 'It is not fair that you do not know we have problems': Perceptual distance and the consequences of male leaders' conflict avoidance behaviours. European Management Journal, 36(1), 105-116. doi:10.1016/j.emj.2017.03.013 


\section{APPENDIX}

Trust

- In this team we know about non-business interests of other people in this group

- In this team, we trust ourselves as people, not just as collaborators

- I'm calm about complying with ethical standards by other team members

- I am not afraid of openly expressing difficult views in this team, because I know that it will not be used against me

- By submitting a request or task to another member of this team I am calm about the quality of the work I have provided.

- By forwarding a request or task to another member of this team, I am confident that I will do it on time.

- If any of this team fails to meet the deadline for completing the task or makes a mistake, it immediately informs the persons affected by this work.

- Team members are eager to ask their colleagues for advice, knowing that they will receive support and will not be assessed as incompetent.

Open discussion of conflict:

- In the team we can openly disagree with each other in the discussion knowing that it will not negatively affect the relationship between us

- When an unclear situation arises, interested people in the team openly and with commitment discuss it

- During the team meetings, participants boldly present their reasons, even if others see things differently

- The leader talks openly about emerging team conflicts, encouraging discussion of them

- Every member of this team regularly receives feedback from others.

- After completing each larger task, we make sure that we give each other feedback

- In our team, by providing feedback, we call specific events and situations

- In our team, we provide ourselves feedback directly after the event it concerns.

Team involvement:

- At the team's meetings you can see a genuine commitment to making decisions for all participants

- We have a way of making decisions as a team

- When making important decisions about the team, we make sure that everyone can express their opinion

- Members of this team are actively looking for ways to get involved in matters that concern them.

- When a decision is made, everyone is involved in its implementation, even if initially they were advocates of another solution.

- We have a clear view of the direction our team is approaching

- We adapt efficiently to change the way the team goal is achieved, even when it requires effort

- In our team we are committed to the implementation of the decision, even knowing that it can change.

Personal accountability:

- In this team, each task has a specific person who is responsible for it

- I am convinced that people in this team feel genuinely responsible for the implementation of their tasks in the highest quality and on time 
- The members of this team are actively looking for the sense and purpose of the tasks that have been commissioned to them

- I see that the members of this team are constantly improving ways to do their job

- Each team member feels co-responsible for the group's results as a whole

- When the task carried out by one of the team members is threatened with failure, I can see how others help him with involvement

- The leader is not the only source of discipline - the team members are mutually responsible

- Everyone knows what is currently a priority in the work of the other team member

Attention to results:

- We regularly monitor how current the task of each of us brings the team closer to its goal

- We regularly look at the results achieved by the team as a whole

- We regularly compare the level of implementation of our tasks with fixed indicators

- We have as a team a tool to monitor the progress of our work

- We get feedback on the quality of our work from internal or external clients

- We improve our work based on feedback from internal and external clients

- Team members consciously and confidently make concessions in matters that matter to them if it serves the good of the team

- The team celebrates common successes and experiences a lot of failure 